Ideological Asymmetries in Social Psychological Research: Rethinking the Impact of Political Context on Ideological Epistemology

\author{
Ingrid J. Haas \\ Department of Political Science \\ Center for Brain, Biology, and Behavior \\ University of Nebraska-Lincoln
}

Manuscript draft (2020.01.29). Please cite as: Haas, I. J. (in press). Ideological asymmetries in social psychological research: Rethinking the impact of political context on ideological epistemology. Psychological Inquiry.

Corresponding Author:

Ingrid J. Haas

Department of Political Science

University of Nebraska-Lincoln

531 Oldfather Hall

Lincoln, NE 68588

Phone: 402-472-2173

Email: ihaas2@unl.edu 


\section{Ideological Asymmetries in Social Psychological Research: \\ Rethinking the Impact of Political Context on Ideological Epistemology}

“...we are not afraid to follow truth wherever it may lead, nor to tolerate any error so long as reason is left free to combat it."

(Thomas Jefferson to William Roscoe, December 27, 1820)

In the target article, Clark and Winegard (this issue) put forth an evolutionary argument for the idea that liberals and conservatives are equally motivated by tribalism and that this motivation for groupishness often biases relevant information processing in a politically expedient direction for both groups. They discuss the implications for social science research, suggesting that scientists are not immune from ideological epistemology and this has implications for how researchers approach the study of ideological differences, as well as bias in the scientific process more generally. I agree that scientists must be cognizant of their own ideological bias given that it likely does have an impact on the selection of research questions, and given recent surveys of social psychologists, appears to also influence how they evaluate the research conducted by peers (Inbar \& Lammers, 2012). I begin this commentary with some discussion of areas of agreement—namely, that I agree much of the research focused on studying ideological differences between liberals and conservatives has been oversimplified and that these differences are likely to be much more nuanced and influenced by political context. While I agree with the basic premise that both liberals and conservatives have tendencies toward tribalism that may result in biased 
information processing, I argue here that there may still be asymmetries in terms of how this bias is expressed, especially in the context of contemporary American politics. I end with consideration of whether it is fair to generalize from recent data showing liberal bias in social psychology (Inbar \& Lammers, 2012; von Hippel \& Buss, 2017) to social science as a whole, examining specifically the potential for differences between social psychology and political science, both in terms of membership and professional norms.

\section{The Role of Political Context}

In general, I agree with the claim put forth by Clark and Winegard (this issue) that both liberals and conservatives can be motivated by ideological values and political group membership to engage in biased information processing-accepting confirming information while challenging or dismissing disconfirming information. Given how pervasive motivated reasoning appears to be (e.g., Kunda, 1990; Lord, Ross, \& Lepper, 1979; Sweeney \& Gruber, 1984; Taber \& Lodge, 2006), it would indeed be surprising if a group of people was entirely immune. However, the tendency to engage in this type of reasoning, what Clark and Winegard (this issue) refer to as ideological epistemology, is likely to depend on affective context and the strength of both ideological values and group identification. It does seem as though this nuance has often escaped the dominant narrative on ideological differences in the field in recent years, which has been to clearly explicate how conservatives are different from liberals in a way that makes these differences seem static rather than dynamic and changing across context and across time. In other words, part of the reason for some of the conflicting findings Clark and Winegard (this issue) outline in the helpful summary in Table 1 may be that 
liberal and conservative traits, characteristics, and behaviors are not static but dynamic, changing over time as a function of situational and social constraints (see e.g., Wheeler et al., 2020).

A nice recent example of this is Federico and Malka's (2018) discussion of how issue domain and political context influence the link between dispositions and ideology, showing nuance in the link between needs for security and certainty and political conservatism. Other good examples of research that more broadly considers context include Washburn and Skitka's (Washburn \& Skitka, 2017) work demonstrating that both liberals and conservatives engage in science denial depending on issue domain and work showing that liberals and conservatives show similar levels of political (in)tolerance when asked about politically dissimilar groups (Brandt, Reyna, Chambers, Crawford, \& Wetherell, 2014; Sullivan, Piereson, \& Marcus, 1979).

A lack of attention to political context can lead to overgeneralization of existing research findings to new domains, rather than consideration of how liberals and conservatives may show more or less similarity depending on the domain of interest. Not to pick on Moral Foundations Theory, specifically, but just to illustrate this idea with an (imperfect) example--while Haidt and colleagues have argued that conservatives care more about loyalty when making moral decisions (Haidt, 2007; Haidt \& Graham, 2007), this finding has arguably been overgeneralized to argue that conservatives always care more about loyalty than liberals. However, work in political science has shown that group loyalty predicts partisan attachment equally for Democrats and Republicans (Clifford, 2016), so perhaps liberals do care equally about loyalty in domains other than moral decision making. If the idea that conservatives care about 
loyalty and liberals do not becomes the dominant narrative in the field, researchers (and reviewers and editors) are then surprised when work challenges the dominant view and this likely complicates the publication process. But, we rarely consider whether the dominant view was justified in the first place or resulted from a lack of attention to external validity (i.e., generalization across context) in social psychology. Given that consideration of the role of context does complicate the research process, placing additional limits on external validity and adding uncertainty, ideologically-congruent bias in the publication process probably becomes more likely (Clark \& Winegard, this issue). This context-dependent interpretation of findings on ideological differences is not limited to the study of personality traits-indeed, a growing literature also suggests that the link between affective responses and political ideology may be more complicated than initially argued.

Research in social and political psychology has argued that conservatives are more sensitive than liberals to negative affect or emotional states, including uncertainty, threat, fear, and disgust. The prevailing view in this literature has been that conservatives are more likely than liberals to be motivated by uncertainty and threat (e.g., Jost, Glaser, Kruglanski, \& Sulloway, 2003; Jost et al., 2007), that conservatives show an overall negativity bias (e.g., Hibbing, Smith, \& Alford, 2014; Shook \& Fazio, 2009), and that conservatives are more likely to respond to threatening and disgusting stimuli (e.g., Oxley et al., 2008; Smith, Oxley, Hibbing, Alford, \& Hibbing, 2011). However, there is reason to believe that these effects may not always been so clear cut. For example, some work has shown conservatives show greater neural response to disgust- but not fear-related stimuli (Ahn et al., 2014) and a recent pre-registered 
replication found no difference between liberals and conservatives in physiological responses to threatening stimuli (Bakker, Schumacher, Gothreau, \& Arceneaux, in press).

In some of our past work we found only a marginal difference between liberals and conservatives response to threat, showing that liberals and conservatives largely responded similarly to threat and uncertainty when the outcome of interest was political tolerance (Haas \& Cunningham, 2014). Both liberals and conservatives showed a decrease in political tolerance in response to uncertain threats. In some ongoing work, we find that both liberals (Democrats) and conservatives (Republicans) respond to political threat by increasing endorsement of politically-relevant conspiracy theories (Schneider \& Haas, 2020). But, in other work I do find differences in how liberals and conservatives respond to threat and uncertainty when the outcome of interest is support for political compromise (Haas, 2016). While liberals and conservatives in general tend to be equally supportive (or not) of compromise, I found in this work that conservatives were more likely than liberals to decrease support for compromise in response to uncertain threats. And, in the conspiracy work, we do find that the effect of threat on conspiracy endorsement changes over time as a function of who currently holds political power-threat is more likely to motivate conspiracy endorsement for individuals who are lacking political power (i.e., Democrats after the election of President Donald Trump in 2016; Schneider \& Haas, 2020). It is worth noting that compromise work mentioned above (Haas, 2016) was conducted while Barack Obama was President, so I think it remains an open question whether conservatives would always show this effect relative to liberals, or if these effects would be further moderated by political context (i.e., 
political party in control of the presidency). Taken together, this work suggests we need to do more than just look at how liberals and conservatives respond to emotional stimuli, but how those responses lead to (or not) related changes in their political behavior. Emotion and politics is one example domain in which I think political context likely plays a large role in how we approach trying to understand ideological differences, but Federico and Malka (2018) demonstrate context is also relevant for work on personality and dispositions and call for broader application of these ideas to work in social and political psychology. While social psychology has not always placed high value on external validity (Mook, 1983), this is a mistake for social psychologists interested in studying politics.

\section{Political Asymmetries}

Clark and Winegard (this issue) argue that liberals and conservatives are equally tribally motivated. On page 17 , they write "We believe that it is highly unlikely that there is a large asymmetry between modern Democrats and Republicans in these ideologically driven cognitive tendencies... it is difficult to imagine that one coalition (Democrats) could compete effectively against another (Republicans) if their members were systematically less tribally motivated" (Clark \& Winegard, this issue). This argument seems plausible on the surface, as both groups do likely care about those others they identify as ingroup members. However, it is worth pointing out a couple differences between how social psychologists and political scientists think about ideology that may lead us to re-evaluate this argument. Namely, while social psychologists, on average, have tended to focus on ideology as something that is static 
(with some exceptions, see e.g., Bonanno \& Jost, 2006), and been less concerned about party identification (or the relationship between the two), political scientists tend to be more likely to discuss the relationship between ideology and party, and how that relationship has shifted over time. Psychologists are also more likely to measure political identification by asking people whether they are liberal or conservative, whereas political scientists are sometimes measuring policy attitudes or values instead. These may sometimes align, but they are not the same thing, as it is possible for people to show loyalty to a party in the absence of holding strong ideological principles (Barber \& Pope, 2018) or adhere to an ideology in the absence of strong or consistent issue positions (Mason, 2018a). Political coalitions do shift over time as parties become stronger or weaker relative to their opponents, perhaps in part due to differential strength in tribal motivations of group members (which are also shifting across time and political context; see e.g., Wheeler et al., 2020). In other words, rather than tribalism predicting political stability, changes in tribal motivation may be one of the primary drivers of party realignment and voter defection. This leads to a couple important but related questions—are liberals and conservatives equally tribally motivated? And, have tribal motivations shifted over time, as a consequence (or a cause) of partisan realignment?

In Figure 1, Clark and Winegard (this issue) describe the difference between ideologues and apparatchiks (see also Rauch, 2015). Apparatchiks are motivated more by party concerns and support compromise when necessary, whereas ideologues are driven primarily by ideology, are less willing to compromise, and will leave the party if their sacred values are not satisfied. If we consider political ideology in the context of 
contemporary American political parties, there is a body of work suggesting important asymmetries in how liberals (Democrats) versus conservatives (Republicans) are approaching ideological conflict that may indeed mean that one party (Republicans) is more effectively harnessing ideological motivations than the other (Democrats). This argument has been made by scholars with diverse training, including a linguist who has argued that Republicans are more adept than Democrats at using language to effectively frame policy positions (Lakoff, 1995), and a clinical psychologist who argued that Republicans are more effective than Democrats at harnessing emotion to persuade voters (Westen, 2007).

In recent years, political scientists have argued that party realignment has led to a Republican Party that is more socially and culturally homogenous than the Democratic Party (Mason, 2018b; Mason \& Wronski, 2018). Mason and colleagues show that strength of partisan attachment has increased for those who are identified with both parties, but this effect is stronger for Republicans given the homogeneity of the group. Related, political scientists have also pointed out that the contemporary Republican Party serves as a vehicle for conservative ideology in a way that the Democratic Party does not for liberal ideology (Grossman \& Hopkins, 2016). They argue that the current Republican Party appeals to abstract conservative values, while the Democratic Party focuses more on concrete policy change that appeals to a broad coalition of different liberal groups. This united messaging is also evident in the pervasive impact of conservative media. While cable news has evolved in such a way that both conservative and liberal media outlets exist, conservative outlets like Fox News have had much larger viewership and larger impact on political knowledge and beliefs as a result 
(Cassino, 2016). In recent years, there is even evidence of more direct coordination between conservative media (i.e., Fox News) and the Republican Party establishment (Azari, 2016). Taken together, this work suggests that Democrats may behave more like apparatchiks compromising when necessary to support the party coalition, whereas Republicans behave more like uncompromising ideologues focused on pursuing a conservative ideological agenda. I mention this work not because it invalidates work conducted by social psychologists, but because I think we need to do more to integrate work across these fields in a truly interdisciplinary manner that includes consideration of both micro- and macro-level phenomena.

It is difficult, if not impossible, to study ideology devoid of political context, given most work in social psychology is influenced by historical context, whether that context is clearly visible or not at the time (this is not a new idea; see e.g., Cherry, 1995). Research on political ideology should start to focus more on the link between ideology and party, and interpretation of social psychological research on ideology should consider political context. To facilitate this process, researchers should, as a more concrete example, include information on the time period in which data was collected (some do, but I do not think this is common practice in social psychology). This is likely to influence both the research questions we ask and may also limit the external validity of our findings in terms of being able to generalize across time and political context.

\section{Ideological Bias in the Social Sciences}

Clark and Winegard (this issue) argue that recent events have increased awareness of liberal bias in the social sciences. However, the primary examples they 
discuss come from the field of social psychology, rather than the social sciences as a whole (I do not fault them for this, given recent data on the social sciences as a whole is hard to find). While the assumption that social scientists, on average, skew liberal may prove true, this claim does not seem warranted based on the data presented in the paper. It seems important not to overgeneralize from the field of social psychology, which could prove to be even more ideologically homogenous than some other fields within the social sciences, or even among subfields within psychology. Or, social psychology could look similar to other fields and subfields in terms of its political makeup, but I am not sure we know that based on extant data. There may be reason to believe that individuals with a liberal ideology might be especially attracted to a field like social psychology that, by definition, explains human behavior in terms of social context. Unfortunately, the requisite data to compare current political identification across fields within the social sciences does not exist (at least to my knowledge), so we can only consider the data that do exist. I will focus mainly on social psychology and political science here for simplicity, but future analyses should look at the social sciences more broadly. ${ }^{1}$

The recent surveys examining the political leanings of social psychologists mentioned by Clark and Winegard (this issue) surveyed members of the Society for Personality and Social Psychology (Inbar \& Lammers, 2012) and the Society for Experimental Social Psychology (von Hippel \& Buss, 2017). While the overall response rate was low (27\%), Inbar and Lammers (2012) found that the vast majority of social

\footnotetext{
${ }^{1}$ There are a few papers published on the political leanings of college professors in various fields that might be helpful here, but most present historical rather than recent data (e.g., Eitzen \& Maranell, 1968; Maranell \& Eitzen, 1970; Turner \& Spaulding, 1969). For the sake of space, I do not discuss these further in this commentary, but they generally show social scientists to be liberal (Democrats) on average, with sociologists expressing more liberal views than political scientists, followed by psychologists.
} 
psychologists who responded to the survey identified as socially liberal $(90.6 \%)$ and a smaller majority identified as liberal on economic issues (63.2\%) and foreign policy $(68.6 \%)$. More disturbing than the homogeneity in political identification, they also found that conservatives in the field perceived discrimination and that the strength of liberal identity predicted self-reported willingness to discriminate against conservative scientists (Inbar \& Lammers, 2012).

Interestingly, political science has seemingly not grappled with this issue in the same way social psychology has in recent years. This is perhaps surprising given that (liberal) ideological homogeneity in political science has been raised in the context of recent attempts made by Republican members of Congress to cut all federal funding for political science research from the National Science Foundation (Sides, 2015, June 10). While I could not find recent data on the political leanings of political scientists, surveys conducted in 1959 and 1970 suggested that approximately $75 \%$ of political scientists (members of the American Political Science Association) identified as Democrats and 10-15\% identified as Republicans (Turner \& Hetrick, 1972; Turner, McClintock, \& Spaulding, 1963). A survey conducted in 1980 found a more modest number of Democrats among political scientists-61\%--although the increase was primarily in the number of people identifying as political independents (14\%), rather than any substantial change in the number of Republicans (17\%; Roettger \& Winebrenner, 1983). While response rates were still relatively low in these surveys, they were closer to 50 $60 \%$ and (having been conducted by good political scientists) all three of these surveys relied on probability sampling of APSA members. It is difficult to compare these numbers directly with the data on social psychologists (i.e., Inbar \& Lammers, 2012), as 
the time period differs along with the way identification was measured (ideology versus partisanship), sampling method, and response rates.

Some of the same scholars who conducted the political science surveys also conducted a survey of the political orientations of psychologists in 1961, finding $70 \%$ identified as Democrats and $20 \%$ identified as Republicans (McClintock, Spaulding, \& Turner, 1965). They again used probability sampling, here focused on members of the American Psychological Association, with a 60\% response rate. From this data, it appears that in the 1960s, the number of Democrats in psychology (as a whole) was roughly comparable to that in political science and psychology even had a few more Republicans. In trying to compare these data to the data reported more recently about social psychologists in particular (Inbar \& Lammers, 2012), a number of questions emerge: Are social psychologists identifying as Democrats in higher numbers than psychologists in other subfields of psychology? In higher numbers than political or other social scientists? Or, if surveyed differently, would the number of social psychologists identifying as Democrats perhaps be a bit more modest (closer to $70 \%$ rather than $90 \%)$ ? Before the field of social psychology can really tackle the issue of ideological bias, homogeneity, and epistemology, it seems imperative to collect more data. It would also be interesting to compare whether conservative scholars in other fields within the social sciences perceive discrimination in the same way they appear to in social psychology. I do wonder whether there is a point at which the political views of the majority come to dominate the field in a way that perpetuates political bias, versus the field maintaining a nonpartisan or apolitical approach to science. I agree with Clark and Winegard (this issue) when they state that "Science battles this almost inevitable drift 
toward ideological epistemology not by rooting out the tendency in individuals or even by selecting for particularly dispassionate scientists, but rather by creating an incentive structure that promotes scrutiny, skepticism, and informational battle" (Clark \& Winegard, this issue, pp. 47-48). But, I wonder if simply discussing and publicizing bias in the field goes far enough—we may need to further consider the role of disciplinary norms for scientists engaging in research focused on politics.

Part of why I think it is interesting to compare social psychologists to political scientists, is that I perceive political scientists as being more cognizant of the potential for bias (either actual or perceived) in their work (this is purely anecdotal, based on my own experience working in both fields). This is evidenced, for example, by the fact that the Midwest Political Science Association has an explicit statement on their website that the organization is nonpartisan and does not support or endorse specific political parties or candidates (see https://www.mpsanet.org/About-MPSA/History-of-the-MPSA). Perhaps the field of social psychology, given the implications of our work for public policy, could consider formalizing similar statements through our professional organizations as a way of explicitly signaling to the membership (and the public) that as researchers we should not be taking a political stance. SPSP's website, for example, outlines the mission and goals of the society, which include advocating for relevant public policies, but make no clear statement about abstaining from taking a specific political stance (http://www.spsp.org/about). The same appears to be true for the Society for the Study of Psychological Issues (https://www.spssi.org/index.cfm?fuseaction=Page.ViewPage\&pageld=1963) and broader psychology organizations like APS 
(https://www.psychologicalscience.org/about/who-we-are). All of these organizations advocate for the use of research to inform public policy (which is an admirable goal), and while they do not take an explicit political stance, it is possible that the implicit politics of the field are visible in, for example, the list of issue areas chosen to highlight (e.g., social justice).

If it is the case that psychology advocates for public policy based on science, regardless of ideology or political party, then perhaps it is worth signaling that more explicitly through our professional organizations. Given the results of the survey conducted by Inbar and Lammers (2012), showing that social psychologists are overwhelmingly liberal on social issues but more diverse on economic issues and foreign policy, an apolitical stance may be worth signaling especially when psychologists are informing policy on social issues, as they often are. It may be obvious, but this goes beyond the internal politics of the field and internal debates about the rigor of our science, to implications for public policy and public perceptions of scientists. It has real implications for things like whether members of Congress are willing to support federal research funding for the social sciences, and I think all scientists need to take this seriously and reflect on the extent to which their own personal politics may be influencing their work (see Clark \& Winegard, this issue). Researchers should also consider how the broader political context may be changing how their own personal politics are expressed by, for example, leading them to advocate more forcefully for specific positions when their own views are perceived to be under threat by the current power dynamics in American politics. 


\section{Conclusion}

In sum, while I agree with many of the arguments raised by Clark and Winegard (this issue), we should continue to debate the degree to which liberals and conservatives are equally motivated by tribalism, especially in the context of contemporary American politics. While there is no doubt that personal political views influence the questions that scientists deem important, I do wonder to what extent the ideological biases recently observed in the field of social psychology generalize to the social sciences as a whole (and political science in particular). I am also left wondering where we go from here. I think that Clark and Winegard (this issue) are correct that limiting the impact of ideological bias may require changes to the incentive structure for social scientists and I wonder if professional organizations in social psychology, in particular, should consider making more explicit calls for research to remain separate from personal politics. More importantly, the argument (Clark \& Winegard, this issue) that people value group loyalty and ideology over truth is a troubling one and future research should continue to examine the circumstances under which truth wins out over ideology and group loyalty, both in politics and in science.

\section{Note}

Address correspondence to Ingrid J. Haas, Department of Political Science, University of Nebraska-Lincoln, 511 Oldfather Hall, Lincoln, NE 68588. Email: ihaas2@unl.edu 


\section{References}

Ahn, W.-Y., Kishida, Kenneth T., Gu, X., Lohrenz, T., Harvey, A., Alford, John R., . . . Montague, P. R. (2014). Nonpolitical images evoke neural predictors of political ideology. Current Biology, 24, 1-7. doi: 10.1016/j.cub.2014.09.050

Azari, J. R. (2016). How the News Media Helped to Nominate Trump. Political Communication, 33(4), 677-680. doi: 10.1080/10584609.2016.1224417

Bakker, B. N., Schumacher, G., Gothreau, C., \& Arceneaux, K. (in press).

Conservatives and liberals have similar physiological responses to threats. Nature Human Behaviour.

Barber, M., \& Pope, J. C. (2018). Does Party Trump Ideology? Disentangling Party and Ideology in America. American Political Science Review, 113(1), 38-54. doi: $10.1017 / \mathrm{s} 0003055418000795$

Bonanno, G. A., \& Jost, J. T. (2006). Conservative shift among high-exposure survivors of the September 11th terrorist attacks. Basic and Applied Social Psychology, 28, 311-323.

Brandt, M. J., Reyna, C., Chambers, J. R., Crawford, J. T., \& Wetherell, G. (2014). The Ideological-Conflict Hypothesis: Intolerance Among Both Liberals and Conservatives. Current Directions in Psychological Science, 23(1), 27-34. doi: $10.1177 / 0963721413510932$

Cassino, D. (2016). Fox News and American politics: How one channel shapes American politics and society. New York: Routledge.

Cherry, F. (1995). The 'stubborn particulars' of social psychology. 
Clark, C. J., \& Winegard, B. M. (this issue). Tribalism in war and peace: The nature and evolution of ideological epistemology and its significance for modern social science. Psychological Inquiry.

Clifford, S. (2016). Individual Differences in Group Loyalty Predict Partisan Strength. Political Behavior, 39(3), 531-552. doi: 10.1007/s11109-016-9367-3

Eitzen, D. S., \& Maranell, G. M. (1968). The political party affiliation of college professors. Social Forces, 47(2), 145-153.

Federico, C. M., \& Malka, A. (2018). The Contingent, Contextual Nature of the Relationship Between Needs for Security and Certainty and Political Preferences: Evidence and Implications. Advances in Political Psychology, 39, 348. doi: 10.1111/pops. 12477

Grossman, M., \& Hopkins, D. A. (2016). Asymmetric politics: Ideological Republicans and group interest Democrats.

Haas, I. J. (2016). The impact of uncertainty, threat, and political identity on support for political compromise. Basic and Applied Social Psychology, 38(3), 137-152.

Haas, I. J., \& Cunningham, W. A. (2014). The uncertainty paradox: Perceived threat moderates the effect of uncertainty on political tolerance. Political Psychology, 35(2), 291-302.

Haidt, J. (2007). The new synthesis in moral psychology. Science, 316, 998-1002.

Haidt, J., \& Graham, J. (2007). When morality opposes justice: Conservatives have moral intuitions that liberals may not recognize. Social Justice Research, 20, 98116. 
Hibbing, J. R., Smith, K. B., \& Alford, J. R. (2014). Differences in negativity bias underlie variations in political ideology. Behavioral and Brain Sciences, 37(3), 297-307. doi: $10.1017 / S 0140525 \times 13001192$

Inbar, Y., \& Lammers, J. (2012). Political Diversity in Social and Personality Psychology. Perspect Psychol Sci, 7(5), 496-503. doi: 10.1177/1745691612448792

Jost, J. T., Glaser, J., Kruglanski, A. W., \& Sulloway, F. J. (2003). Political conservatism as motivated social cognition. Psychological Bulletin, 129, 339-375.

Jost, J. T., Napier, J. L., Thorisdottir, H., Gosling, S. D., Palfai, T. P., \& Ostafin, B. (2007). Are needs to manage uncertainty and threat associated with political conservatism or ideological extremity? Personality and Social Psychology Bulletin, 33, 989-1007.

Kunda, Z. (1990). The case for motivated reasoning. Psychological Bulletin, 108, 480498.

Lakoff, G. (1995). Metaphor, morality, and politics or, why conservatives have left liberals in the dust. Social Research, 62(2), 1-22.

Lord, C. G., Ross, L., \& Lepper, M. R. (1979). Biased assimilation and attitude polarization: The effects of prior theories on subsequently considered evidence. Journal of Personality and Social Psychology, 37, 2098-2109.

Maranell, G. M., \& Eitzen, D. S. (1970). The effect of discipline, region, and rank on the political attitudes of college professors. The Sociological Quarterly, 11(1), 112118. 
Mason, L. (2018a). Ideologues without Issues: The Polarizing Consequences of Ideological Identities. Public Opinion Quarterly, 82(S1), 866-887. doi: 10.1093/poq/nfy005

Mason, L. (2018b). Uncivil agreement: How politics became our identity. Chicago: University of Chicago Press.

Mason, L., \& Wronski, J. (2018). One Tribe to Bind Them All: How Our Social Group Attachments Strengthen Partisanship. Advances in Political Psychology, 39, 257277. doi: $10.1111 /$ pops. 12485

McClintock, C. G., Spaulding, C. B., \& Turner, H. A. (1965). Political orientations of academically affiliated psychologists. American Psychologist, 20(3), 211.

Mook, D. G. (1983). In defense of external invalidity. American Psychologist, 379-387.

Oxley, D. R., Smith, K. B., Alford, J. R., Hibbing, M. V., Miller, J. L., Scalora, M., . . . Hibbing, J. R. (2008). Political attitudes vary with physiological traits. Science, $321,1667-1670$.

Rauch, J. (2015). Political realism: How hacks, machines, big money, and back-room deals can strengthen American democracy. Washington, D.C.: Brookings Institution Press.

Roettger, W. B., \& Winebrenner, H. (1983). The voting behavior of American political scientists: The 1980 presidential election. Western Political Quarterly, 36(1), 134148.

Schneider, S. P., \& Haas, I. J. (2020). Political threat, ideology, and conspiracy endorsement. Manuscript submitted for publication. 
Shook, N. J., \& Fazio, R. H. (2009). Political ideology, exploration of novel stimuli, and attitude formation. Journal of Experimental Social Psychology, 45(4), 995-998.

Sides, J. (2015, June 10). Why Congress should not cut funding to the social sciences, The Washington Post.

Smith, K. B., Oxley, D., Hibbing, M. V., Alford, J. R., \& Hibbing, J. R. (2011). Disgust sensitivity and the neurophysiology of left-right political orientations. PLoS One, 6(10), e25552.

Sullivan, J. L., Piereson, J., \& Marcus, G. E. (1979). An alternative conceptualization of political tolerance: Illusory increases 1950s-1970s. American Political Science Review, 73, 781-794.

Sweeney, P. D., \& Gruber, K. L. (1984). Selective exposure: Voter information preferences and the Watergate affair. Journal of Personality and Social Psychology, 46, 1208-1221.

Taber, C. S., \& Lodge, M. (2006). Motivated skepticism in the evaluation of political beliefs. American Journal of Political Science, 50, 755-769.

Turner, H. A., \& Hetrick, C. C. (1972). Political activities and party affiliations of American political scientists. Western Political Quarterly, 25(3), 361-374.

Turner, H. A., McClintock, C. G., \& Spaulding, C. B. (1963). The political party affiliation of American political scientists. Western Political Quarterly, 16(3), 650-665.

Turner, H. A., \& Spaulding, C. B. (1969). Political attitudes and behavior of selected academically-affiliated professional groups. Polity, 1(3), 309-336.

von Hippel, W., \& Buss, D. M. (2017). Do ideological driven scientific agendas impede understanding and acceptance of evolutionary principles in social psychology? In 
J. T. Crawford \& L. Jussim (Eds.), The politics of social psychology (pp. 7-25). New York: Psychology Press.

Washburn, A. N., \& Skitka, L. J. (2017). Science Denial Across the Political Divide:

Liberals and Conservatives Are Similarly Motivated to Deny Attitude-Inconsistent Science. Social Psychological and Personality Science, 9(8), 972-980. doi: $10.1177 / 1948550617731500$

Westen, D. (2007). The Political Brain: The Role of Emotion in Deciding the Fate of the Nation. New York: Public Affairs.

Wheeler, N. E., Allidina, S., Long, E. U., Schneider, S., Haas, I. J., \& Cunningham, W. A. (2020). A predictive coding account of ideology: Understanding the emergence of bias and polarization through socially shared error minimization. Manuscript submitted for publication. 